Asian J. Med. Biol. Res. 2017, 3 (1), 109-113; doi: 10.3329/ajmbr.v3i1.32045

\author{
Asian Journal of \\ Medical and Biological Research \\ ISSN 2411-4472 (Print) 2412-5571 (Online) \\ www.ebupress.com/journal/ajmbr
}

\title{
Article \\ Surgical management of gid disease in goat at Rangpur district of Bangladesh
}

\author{
Md. Mamunur Rahman ${ }^{1 *}$, Salma Sultana ${ }^{2}$, Md. Zakir Hassan ${ }^{3}$ and Mohammad Mojibur Rahman ${ }^{4}$ \\ ${ }^{1}$ Conservation and Improvement of Native Sheep through Community and Commercial Farming Project, BLRI, \\ Savar, Dhaka, Bangladesh \\ ${ }^{2}$ Department of Physiology, BAU, Mymensingh, Bangladesh \\ ${ }^{3}$ Animal Health Research Division, BLRI, Savar, Dhaka, Bangladesh \\ ${ }^{4}$ Department of Livestock Services, Farmgate, Dhaka, Bangladesh
}

*Corresponding author: Md. Mamunur Rahman, Scientific Officer, Conservation and Improvement of Native Sheep through Community \& Commercial Farming Project, BLRI, Savar, Dhaka-1341, Bangladesh. Phone: +8801719470722; E-mail: mamun13dvm@yahoo.com

Received: 05 March 2017/Accepted: 20 March 2017/ Published: 30 March 2017

\begin{abstract}
The present study was conducted to know about the management of gid disease of goat at Upazila Veterinary Hospital, Rangpur Sadar and District Veterinary Hospital from July, 2011 to December, 2011 in Rangpur district at field level. A total of 12 goats were diagnosed based on history and presenting clinical sings. Furthermore, surgery was performed - in five cases. Circling movement, keeping the head downward to the affected side were major clinical sings. In all the cases, a half moon shaped incision was given at the operative site and after trephining the skull, the cyst was removed. The disease was predominant in female $(91.66 \%)$ than male (16.66\%). Among female goats, the prevalence of gid in pregnant and non-pregnant were $36.36 \%$ and $63.63 \%$ respectively. Black Bengal goats were more susceptible $(91.66 \%)$ to this disease. The method of operation is considered to be useful as treatment in the field level. Alternative way of treatment using anthelmintics or other drugs have studied.
\end{abstract}

Keywords: coenuruse gid; Multiceps multiceps; cyst; cerebral hemisphere; Black Bengal; Jamunapari; surgical management

\section{Introduction}

Goats play an important role in the economy of Bangladesh (Kabir et al., 2004). Many farmers of our country are landless and marginal and they depend on this small ruminant for food and economy (Paul and Saadullah, 1991). So, goat is called "Poor Men's Cow" in our country. The population of goat in Bangladesh is 30.33 million (Banglapedia, 2014).Coenurosis has been reported from time to time in various herbivores and first recorded the since 17th century (William, 1967). The neural form of coenurosis is caused by the larval stage of Multiceps multiceps in goat was reported first from Lahore, Pakistan by Greig, 1977. The disease was reported in goats from Bengal (Dey, 1909) and Ceylon (Southwell, 1912). The disease has been reported in goat by Bhalla and Negi (1962), Sharma and Tyagi, 1975) and Singh and Singh (1972) in Bangladesh. Coenurus cerebralis in the brain and spinal cord of sheep, goat, cattle, horse and wild ruminants and occasionally in cattle during maturity stages (Greig, 1977).

Coenurosis, an endemic disease of goats in Bangladesh, is caused by the invasion of the intermediate stage of a dog tape worm Multiceps multiceps in brain and spinal cord of goat (Dey and Nooruddin, 1996). The disease is also known as Sturdy, Staggers, Goggle turn, Turning sickness, Giggy dents, Water brain, Brendo (Innes and Saunders, 1957). The disease occurs most commonly in sheep, cattle and goats (Bhalerao, 1939; O'Conner, 1963; Blood et al., 1971). The typical clinical signs are the consequences of the localized space occupying lesions of the central nervous system (Blood et al., 1971). The symptom comprises anorexia, dullness, ataxia, 
frequent muscle fasciculation, grinding of teeth, blindness, stumbling, paralysis, incoordination and erratic movement (Abera S and N Abdela, 2016; Doherty et al., 1989). The affected animal leads to death unless the cyst is surgically removed from the brain. The objectives of this study were to handle and manage gid disease through surgical processes to control the disease.

\section{Materials and Methods}

The study was carried out at Upazilla Veterinary Hospital, Rangpur Sadar and District Veterinary Hospital, Rangpur for surgical management of gid disease in goats reared under existing village condition of Rangpur district. A total of 12 goats were selected for surgery among them 11 were black Bengal and 1 was Jamunapari and again 11 of them were female and 1 was male. Among females, 3 were pregnant. Surgery has been done to remove the cyst in only 5 cases out of 12 . The remaining 7 cases have not been handled due to the unwillingness or reluctance of the owners. Diagnosis of intracranial cysts was made on the basis of history, clinical signs and clinical examination (Figure 1). The total animals brought to those two hospitals were assumed as the total samples. Their history and clinical signs were recorded carefully and information about age, sex, and breed were also recorded. The animals showing cessation of feeding, circling movements, repeated bleating and skull softening in the horn base were diagnosed as Gid disease, radiological test or allergic test also done. Unilateral thinning was the most reliable sign both for diagnosis and cyst location, being on the same side. After diagnosis, the cyst was removed by surgical technique. The animal was controlled manually and the operative site was clipped, shaved, scrubbed with soap and water followed by application of tincture of iodine paint over the skin. Razor blade, scalpel handle with blade, rat-tooth forceps, artery forceps, probe, syringe, needle, cotton, nylon or silk suture and 2\% Lignocaine Hydrochloride (Jasocaine A; Jayson, Bangladesh) solution were the materials, used in these operations. Soon after sterilizing the operative site, local blocks around the area were given with 2\% Lignocaine Hydrochloride solution as local anaesthetics. The operation was performed wearing mask, cap, sterilized apron and hand-gloves. One half moon shaped incision on the skin was given to make one flaps, then the skin was detached from the subcutaneous tissue by blunt dissection. Hemorrhage was controlled by applying swabs and artery forceps when necessary. The subcutaneous tissue over the bone was scrapped to expose the bone. Again, the bone was scrapped by scalpel and a circular portion of the bone, sufficiently large enough to remove the cyst was made with the sharp edge of the blade. Local anaesthetics were spread over the meninges and incision was given through it to expose the brain tissue. The cyst was cleared by blunt dissection from the underlying brain tissue. After this, the cyst tended to move quickly towards the exposed brain surface, a process favored by rotation of the head so that the cyst could move downward. This greatly simplified the handling and removal of the cyst. The cyst was then slowly removed by pulling it through simple forceps. Utmost care was taken not to allow the cyst to rupture and fall the fluid in the brain. Attempts were not made to remove the fluid by syringe and needle to avoid accidental drainage of the fluid into the cranial cavity. After removal of the cyst, sulphanilamide powder / or crystalline penicillin powder was dusted on the wound. The incised border of the meninges was brought in apposition to cover the brain tissue. The one flaps of the skin were sutured by interrupted suture with nylon. Tincture of benzoin seal was then applied over the wound. In very weak animals, 100 to $200 \mathrm{ml}$ of $5 \%$ dextrose saline was dripped continuously in to jugular vein during operation. The post operative treatment consisted of daily injection of penicillin \& streptomycin as recommended doses for 5 days, associated with application of anti-histaminic and anti- inflammatory drugs with good nursing and care. The suture was removed between 8-10 days following operation. The wound has found to be completely healed up without any complication. The location and number of cyst removed were recorded. Sex wise distribution of the disease was also recorded.

\section{Results and Discussion}

Out of 12 selected surgical cases, 5 goats were subjected to surgical operations (Figures 2 and 3). The effects of age, sex and breed of animal on the occurrence of gid disease is presented in Tables 1, 2 and 3 respectively. In this study, the disease predominantly $(66.66 \%)$ occured in animals between 1.1 to 2 years of age as shown in Table 1 . The female animals were more vulnerable to the disease $(91.66 \%)$ than males $(16.66 \%)$ as presented in Table 2. These findings support the earlier investigation of gid disease (Sharma and Tyagi, 1975; Doherty et al., 1989). The reasons for the frequent occurrence of the disease in the age group between 1 to 2 year are not clear. Possible reason of this may be the following: the brain at this age may be more suitable for the establishment of infection. Among the female animals studied, pregnant animals were $36.36 \%$. Out of total 12 diseased animals, 11 were Black Bengal (91.66\%). and one was Jamunapari (8.33\%). From the present study, it may be said that Black Bengal goats are more prone to be affected with coenurosis (Table 3). The possible reason of this finding may be due to predominant distribution of Black Bengal goats in our country. All the cysts identified in this 
study, were located in the cerebral hemisphere. This finding agrees with the findings of earlier workers (Sharma and Tyagi, 1975; Nooruddin et al., 1996; Ahmed and Haque, 1975). In the present study, 58.33\% of the cysts were located in the right cerebral hemisphere and $41.66 \%$ in the left cerebral hemisphere. Ahmed and Haque (1975) reported that, in Bengal goat, $47.8 \%$ of the cysts were located in the right cerebral hemisphere and $39.1 \%$ in the left cerebral hemisphere. This finding is almost similar to the finding of the present study. In this study, $91.66 \%$ of the animal examined had one cyst and only $8.33 \%$ had two cysts. Ahmed and Haque (1973), however, reported that $63 \%$ of the cases had one and $32 \%$ had two cysts. All the cysts, which were located in the cerebral hemisphere, were found to be located clinically caudal to the base of the horn. When one cyst was present in this situation, the animal was found to keep its head downward and turning it towards the affected side and circling was observed towards the affected side, which is supported by Soulsby (1968); Blood et al., 1971 and Sharma and Tyagi, 1975. In one case cyst was found on the cerebral hemisphere caudal to the base of both the horns. In this case, circling movement was not observed. The animal remained standing in place. Theses were supported by Ahmed (1973) and Skerritt and Stallbaumer, 1984; Soulsby (1968) suggested that, in many cases, treatment is of no value. However, in this study, the goat showed marked clinical improvement after the surgical removal of the cyst. The results of the present findings support the findings of Skerritt and Stallbaumer (1984) who reported that surgery could be an effective form of treatment for coenuruses and the success rate could be high.

Table 1. Effect of age on gid disease.

\begin{tabular}{lll}
\hline Parameters & No. of animals affected & Percentage of occurrence \\
\hline 1) Up to 1 year & 1 & 8.33 \\
2)Between 1.1-2 years & 8 & 66.66 \\
3)2.1 years or over & 3 & 25 \\
\hline
\end{tabular}

Table 2. Effect of sex on gid disease.

\begin{tabular}{lll}
\hline Parameters & No. of animals affected & Percentage of occurrence \\
\hline 1)Male & 1 & 8.33 \\
2)Female & 11 & 91.66 \\
a)Pregnant & 4 & 36.36 \\
b)Non pregnant & 7 & 63.63 \\
\hline
\end{tabular}

Table 3. Effect of breed on gid disease.

\begin{tabular}{|c|c|c|}
\hline Parameters & No. of animals affected & Percentage of occurrence \\
\hline a) Black Bengal & 11 & 91.66 \\
\hline b) Jamunapari and others & 1 & 8.33 \\
\hline
\end{tabular}

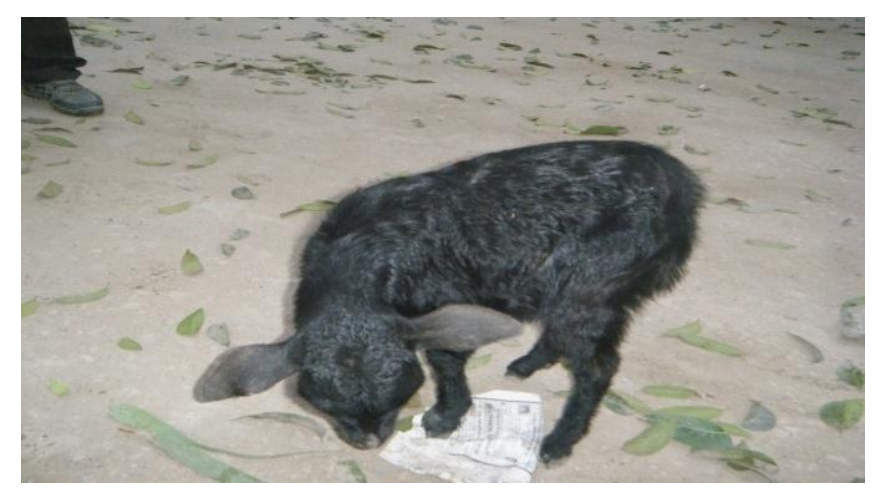

Figure 1. Gid affected goat head downward to the respective side. 


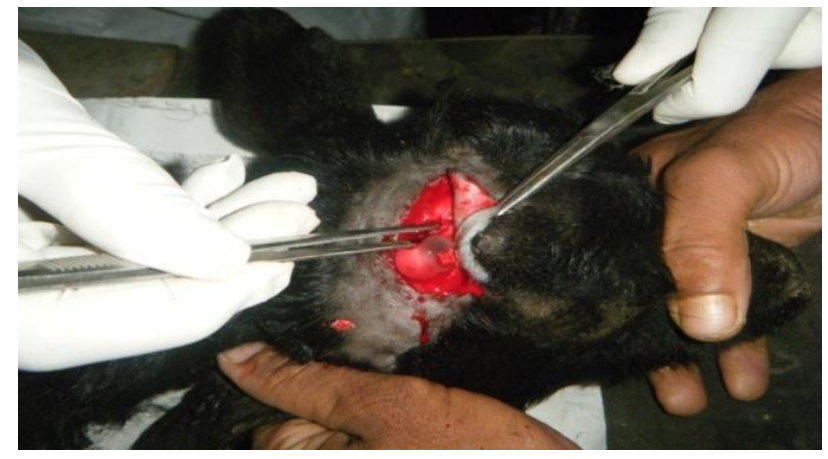

Figure 2. A cyst of Coenurus cerebralis after trephining of the skull in a goat.

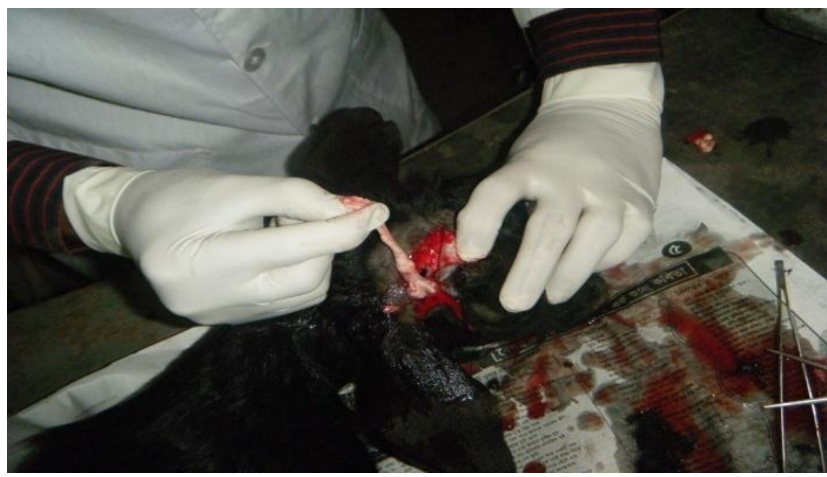

Figure 3. Removal of cyst of Coenurus cerebralis from the skull.

\section{Conclusions}

Clinical study was conducted is 12 affected cases of gid in goats and method of surgical management was observed. History and clinical finding were found to be useful diagnosing tools for clinical cases in field level. Easy technique of surgical extraction of coenurus cyst from the brain under local anaesthesia has been described with no post operative complication and uneventful recovery. The disease more frequently occurred in goats between the age of 1.1 to 2 years and also occurred more commonly in female $(91.66 \%)$ than male $(8.33 \%)$.Therefore, further study should be conducted with clinico-pathological effects of the disease by the species of causal parasites by artificial production and therapeutic Anthelmintics trials to prevent the disease.

\section{Acknowledgements}

The author feels great pleasure to express his deepest of gratitude, sincere appreciation and profound regards to Upazila Veterinary Hospital, Rangpur Sadar and District Veterinary Hospital, Rangpur and owner of the animal.

\section{Conflict of interest}

None to declare.

\section{References}

Abera S and N Abdela, 2016. Public Health and Economic Significance Cerebral Coenurosis in Sheep and Goat: A Review. Acta Parasitologica Globalis, 7: 54-65.

Ahmed JU and MA Haque, 1975. Surgical treatment of coenuruses in goat. Ban.Vet. J., 9: 32-33.

Ahmed JU, MA Haque and A Rahman, 1973. Surgical treatment of coenurosis in goat. Ban.Vet. J., 8: 49-54.

Banglapedia, 2014. Asiatic Society of Bangladesh. Retrieved on Jan 15, 2014. http://www.bpedia.org/B_0453.php.

Bhalerao GD, 1939. A note on a massive natural infection of coenurus gaigeri cyst in goat. Indian Vet. J., 62: 615-616.

Bhalla NP and MS Negi, 1962. Occurence of larval Multiceps multiceps over the heart of a goat. Indian Vet. J., 39: 55-56.

Blood DC, JA Henderson, JH Arundel and CC Gay, 1971. Diseases of the Nervous System, In. Veterinary Medicine, ( $3^{\text {rd }}$ ed.), By: Baillere, Tindal and Cassel, London, 437. 
Dey D, 1909. Coenurus serialis in a goat. J. Trop. Vet. Sci., 4:556-560.

Doherty ML, HF Basset and ML Monoghan, 1989. Outbreak of coenurosis in adult sheep in Ireland. Vet. Rec., 125:185-186.

Greig A, 1977. Coenurosis in cattle. Vet. Rec., 100: 266-268.

Innes JR and Saunders, 1957. Diseases of the Central Nervous System of Domestic Animals and Cimparison with Human Neuro-Pathology, In: advanced Veterinary Science $\left(2^{\text {nd }}\right.$ ed $)$, Academic press INC Publishers, New York., pp. 118-121.

Kabir F, MS Sultana, M Shahjalal, MJ Khan and MZ Alam, 2004. Effect of protein supplementation on growth performance in female goats and sheep under grazing condition. Pakistan J. Nutr., 3: 237-239.

Nooruddin M, AS Dey and MA Ali, 1996. Coenuriasis in Bengal goats of Bangladesh. Small Rumin. Res., 19: $77-81$.

O' Connor JJ, 1965. Dollar's Veterinary Surgery, $\left(4^{\text {th }}\right.$ ed $)$ Baillere, Tindall and Cox, Landon. pp. 480-587.

Paul DC and M Saadullah, 1991. Role of women in homestead of small farm category in an area of Jessore, Bangladesh. Livest. Res. Rural. Dev., 3:23-29.

Sharma HN and RPS Tyagi, 1975. Diagnosis and surgical treatment of coenurosis in goat. Indian Vet. J., 52: 482-484.

Singh KP and SP Singh, 1972. Occurrcce of muliceps cyst in the lymphnode of goat. Indian Vet. J.,l: 11491156.

Skerritt GC and MF Stallbaumer, 1984. Diagnosis and treatment of coenuriasis (gid) in sheep. Vet Rec., 115:399-403.

Soulsby ELJ, 1968. Helminths Arthropods and Protozoa of Domestic Animals (6 $6^{\text {th }}$ ed), Baillere Tindal and Cassel Ltd,London., pp. 438.

Southwell T, 1912. A description of ten new species of cestode parasites from marine fishes of Ceylon, with notes on other cestodes from the same region. Ceylon Marine Biological Report, 1:259-278.

William CP and WC Miller, 1967. Gid or Sturdy, Blacks Veterinary Dictionary $\left(8^{\text {th }}\right.$ ed), Morrison and Cibba Ltd., pp. 383. 